\title{
PROBABILISTIC RISK ANALYSIS \\ OF NUCLEAR SYSTEMS
}

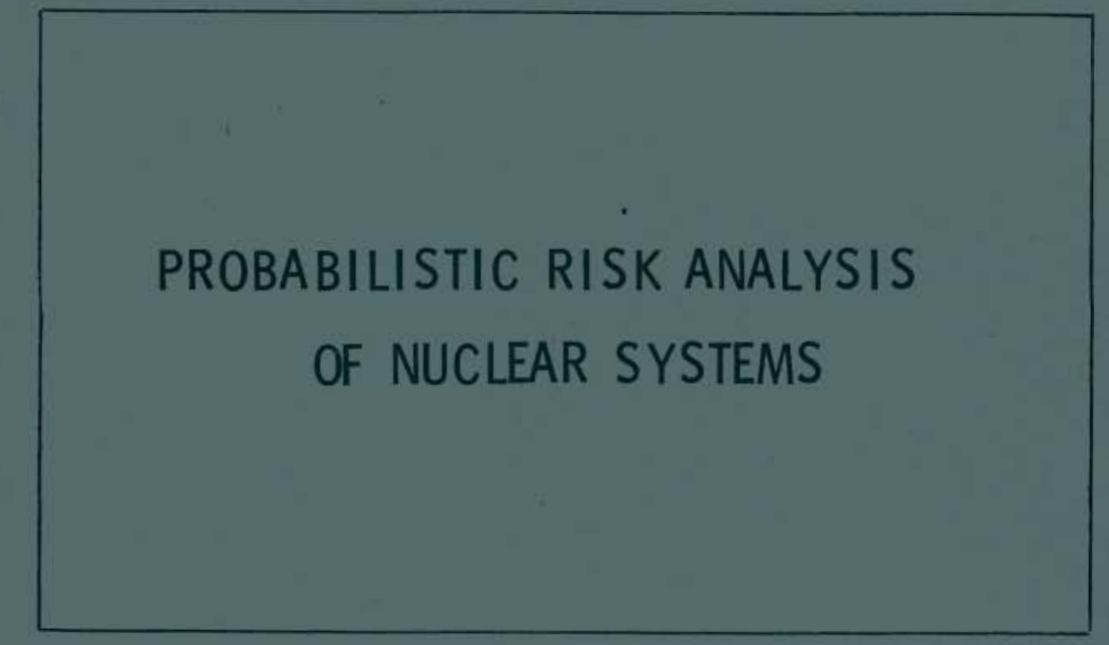

\section{Battelle}

Pacific Northwest Laboratories

Richland, Washington 99352

SEPTEMBER 1974

Q -

$\therefore \therefore$

Prepared for the U.S. Atomic Energy

Commission under Contract AT(45-1):1830 
NOTICE

The report was prepared as an account of work sponsored by the United States Government. Neither the United States nor the United States Atomic Energy Commission, nor any of their employees, nor any of their contractors, subcontractors, or their employees, makes any warranty, express or implied, or assumes any legal liability or responsibility for the accuracy, completeness or usefulness of any information, apparatus, product or process disclosed, or represents that its use would not infringe privately owned rights.

\title{
PACIFIC NORTHWEST LABORATORY operated by \\ BATTELLE \\ for the
}

U.S. ATOMIC ENERGY COMMISSION

Under Contract AT(45-1)-1830

\author{
Printed in the United States of America \\ Available from. \\ National Technical Information Service \\ U.S. Department of Commerce \\ 5285 Port Royal Road \\ Springfield, Virginia 22151 \\ Price: Printed Copy \$4.00; Microfiche \$1.45
}


BNWL -1848

UC $-78 b$

PROBABILISTIC RISK ANALYSIS OF NUCLEAR SYSTEMS

T. H. Smith

September 1974

BATTELLE

PACIFIC NORTHWEST LABORATORIES

RICHLAND, WASHINGTON 99352 


\section{CONTENTS}

$\begin{array}{ll}\text { SUMMARY } & 1\end{array}$

I. INTRODUCTION 2

II. PREVIOUS APPROACHES 3

III. A PROBABILISTIC APPROACH TO RISK ANALYSIS 22

IV. INTEGRATION OF THE APPROACH WITH FAULT TREE METHODOLOGY 33

$\begin{array}{lr}\text { REFERENCES } & 39\end{array}$ 


\section{LIST OF FIGURES}

1 Example of Farmer Event Spectrum: Frequency Versus Quantity Released for Depressurization Through a 24-inch Breach

2 Release Criterion (Proposed by Farmer)

3 Examples of Event Frequency Distribution for Betace ${ }^{\circledR}$ Nuclear Battery

4 Examples of Estimated Distribution of Conditional Probability of Breach for Betace ${ }^{\circledR}$ Nuclear Battery

5 Frequency Distribution of Observed Strengths

6 Predicted Frequency Distribution of Containment Breaches for 20,000 Patients with Betace ${ }^{\circledR}$ Nuclear Batteries

7 Generalized Web of Events in Vehicle Accidents

8 Simplified Example Depicting the Use of Fault Trees for Handling Spectra Involved in Secondary Failures

9 Primary and Secondary Failures 


\title{
PROBABILISTIC RISK ANALYSIS OF NUCLEAR SYSTEMS
}

\author{
T. H. Smith
}

\section{SUMMARY}

Traditional "worst-case" or "maximum credible accident" methods of nuclear safety and risk analysis can be misleading. Realistic evaluation of event frequency and severity and of dispersed radionuclides requires treatment of several probability spectra. Such treatment is needed because initiating events vary in severity and releases vary in quantity and rate.

This report stresses the need for including probabilistic considerations in nuclear risk analyses. Although the potential application is general, certain aspects of the treatment are of special interest for transportation and waste management studies.

Previous methods of quantitative risk calculation for nuclear systems are reviewed. A method of accounting for probabilistic considerations is derived, drawing from the literature review. The approach is felt to be more important than the particular equations derived. The equations could be changed to suit different requirements without sacrificing the basic intent of the method.

Special effort is directed toward an approach compatible with existing fault tree and radionuclide transport methodology. Calculated accident frequencies and release quantities are weighted to give a realistic measure of risk. Frequency distributions of the most important parameters are included. Ways are discussed of simplifying the complete equations into more readily usable forms for preliminary studies. The completeness (and complexity) of the analysis can be varied to suit the required accuracy and the availability of data.

This study was performed for the AEC Division of Waste Management and Transportation in support of the systems safety task of the Waste Fixation Program for commercial high-level radioactive waste. 
BNWL-1848

I. INTRODUCTION

As early as 1967, Farmer (1) stressed the need for a probabilistic approach in nuclear risk analyses:

... No engineering plant and no structure is entirely risk-free, and there is no. logical way of differentiating between credible and incredible accidents. The incredible is often made up of a combination of very ordinary events-for example, the breakdown or deterioration that occurs in normal plants and their measuring instruments--and the credible may be exceedingly improbable. The logical way of dealing with this situation is to seek to assess the whole spectrum of risks in a quantity-related manner...

Building upon concepts dating back to 1955, Farmer proposed a risk criterion in the form of a release quantity vs. probability spectrum.

This approach has been widely adopted and extended in several safety studies. (2-10) In practice, however, the "spectrum" approach is only slowly displacing the "maximum credible" approach. This delay may be partly attributable to the apparent tendency of the public to focus on consequences more than on probabilities. Furthermore, the "maximum credible" approach is simpler to use: One merely selects the maximum "credible" accident and thoroughly analyzes this case only, because all other credible accidents are judged to be of lesser consequences.

There are several drawbacks to the "maximum credible" approach, some of which are being hammered home by critics of nuclear power: (1) Events considered to be "not credible" have happened. (11)

Here is the incredible conclusion to this report: "In an actual accident condition, this occurrence is not credible because the $B$ diesel being disabled (before the $A$ diesel failed to start) represents a single failure and the solenoid valve failing is a second failure. This plant was not designed to be protected against double failures."

The phrase "not credible" is nuclear engineering talk for not possible. Yet, it happened, and the fact that the plant was not designed to protect against it is an absurd excuse...

An event which was considered "not credible" yesterday may have to be revised as "credible" tomorrow after it happens today. (2) The credibility of an event is, by definition, a subjective matter; what is not 
credible to one person may be credible to another observer. (3) As demonstrated later, few situations involve a curve of probability of occurrence vs. event severity which sharply falls to zero at a given severity level, as the "maximum credible" theory implies. (4) Discussion centering only on "maximum credible" events tends to arouse fear in the public.

While the Farmer "spectrum" approach basically overcomes the first three objections, difficulties do remain: (1) The required data input is greater and calculations for manipulating the data are more involved. Methods for minimizing this difficulty are described later. Farmer (1) stated: "It may be thought that the mathematical terminology and form of presentation require exactitude in analysis. This is not so; informed opinion can be expressed in the terms required for this analysis with greater meaning than is conveyed by the safety language now used." (2) Even the "spectrum" approach cannot treat every accident which could happen. The human imagination is limited; thus there are potential accidents we are incapable of imagining. (3) (3) The spectrum approach reduces the emphasis on severe accidents by treating the entire spectrum of accidents and the probability of each. However, accidents on the extreme tail of the probability curve may be even more severe than the corresponding "maximum credible" condition. For most safety analysts, this causes no worry because the risk (generally defined as consequences $X$ probability) will be seen to peak in the moderately severe accident region, not in the extreme release cases nor in relatively frequent small releases. The public, unfortunately, may focus on these extreme accidents. In spite of these deficiencies, at least some elements of the Farmer approach are felt necessary in any rigorous nuclear risk analysis.

\section{PREVIOUS APPROACHES}

A. Farmer ${ }^{(1)}$ dealt with the spectrum of release quantity vs. probability. Assumptions of possible modes of plant failure or maloperation lead to estimations of the probability of the failure and assessment of the consequences. In fact, each initiating fault generally has its own 
spectrum of release quantity vs. probability. Farmer analyzed a typical GCR coolant fault as an example. A decision tree was drawn to show the possible operation or nonoperation of safety systems following the initiating fault. From thermal transient calculations, a series of terminal events was identified, with each of which was associated one value for the frequency of occurrence and another value for expected release quantity. Figure 1 shows these points plotted as probability (in terms of reactor years between releases) versus consequences (in equivalent curies groundlevel release of ${ }^{131} \mathrm{I}$ ). The full safety evaluation comprises a dense spectrum of events with associated probabilities and consequences, producing many more points.

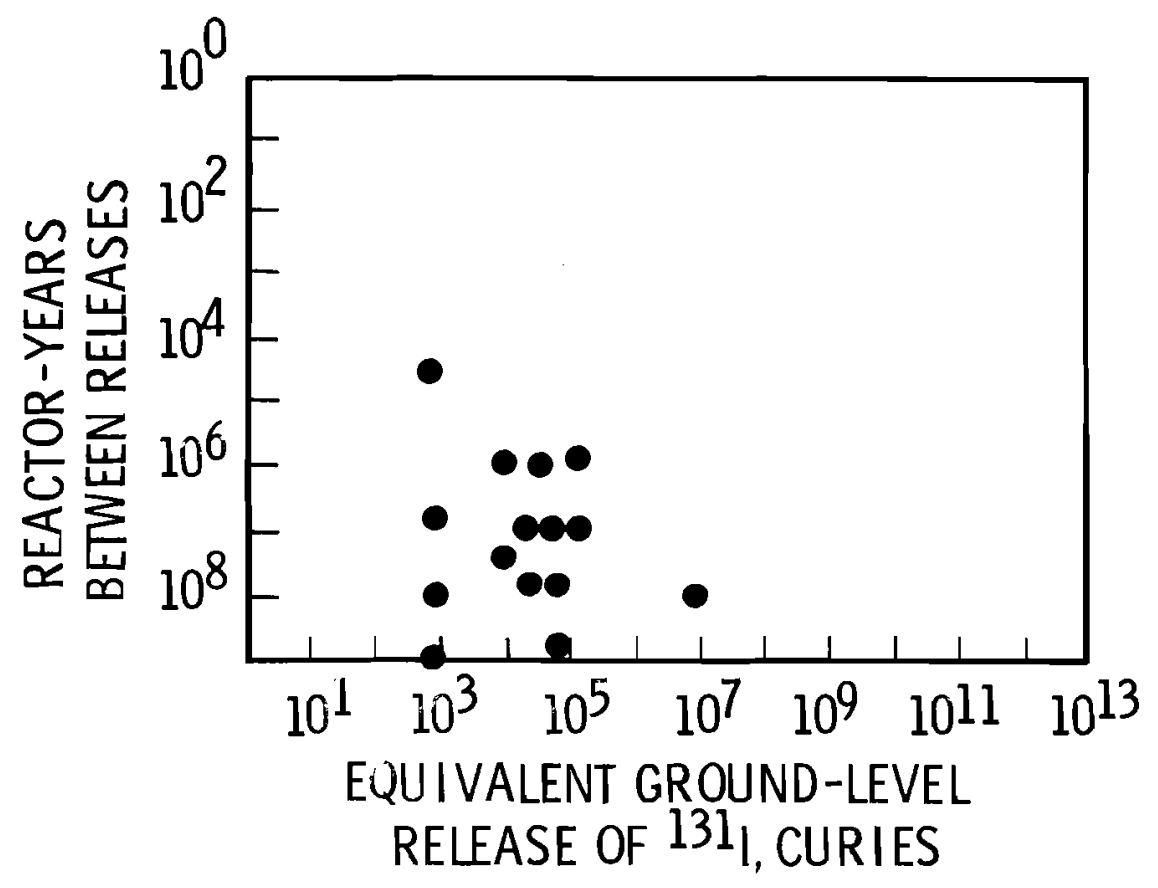

FIGURE 1. Example of Farmer Event Spectrum: Frequency Versus Quantity Released for Depressurization Through a 24-in. Breach 
If a line of slope -1 were drawn on Figure 1 , points of equal risk in curies release per year would be connected. Such a line might be used as an upper boundary safety criterion. The great majority of points such as those in Figure 1 would lie well within the safe zone. A few points might lie near the boundary line. Points lying outside the line would represent unacceptable hazards requiring correction.

This report does not address the question of where the limit line should be drawn. Such a question has implications which lie outside purely engineering considerations. Farmer, however, made the following assumptions: (1) Most people would apply a heavier penalty against the possibility of a large release than against a small release. The boundary slope was, therefore, changed to -1.5. (a) (2) The slope was reduced at small releases to minimize nuisance effects. (3) The line location was determined by considerations of individual and population risk and public reaction. Farmer's proposed release criterion is the curve shown in Figure 2, in terms of accident probability $P$ vs. equivalent ${ }^{131}$ I release quantity $R$.

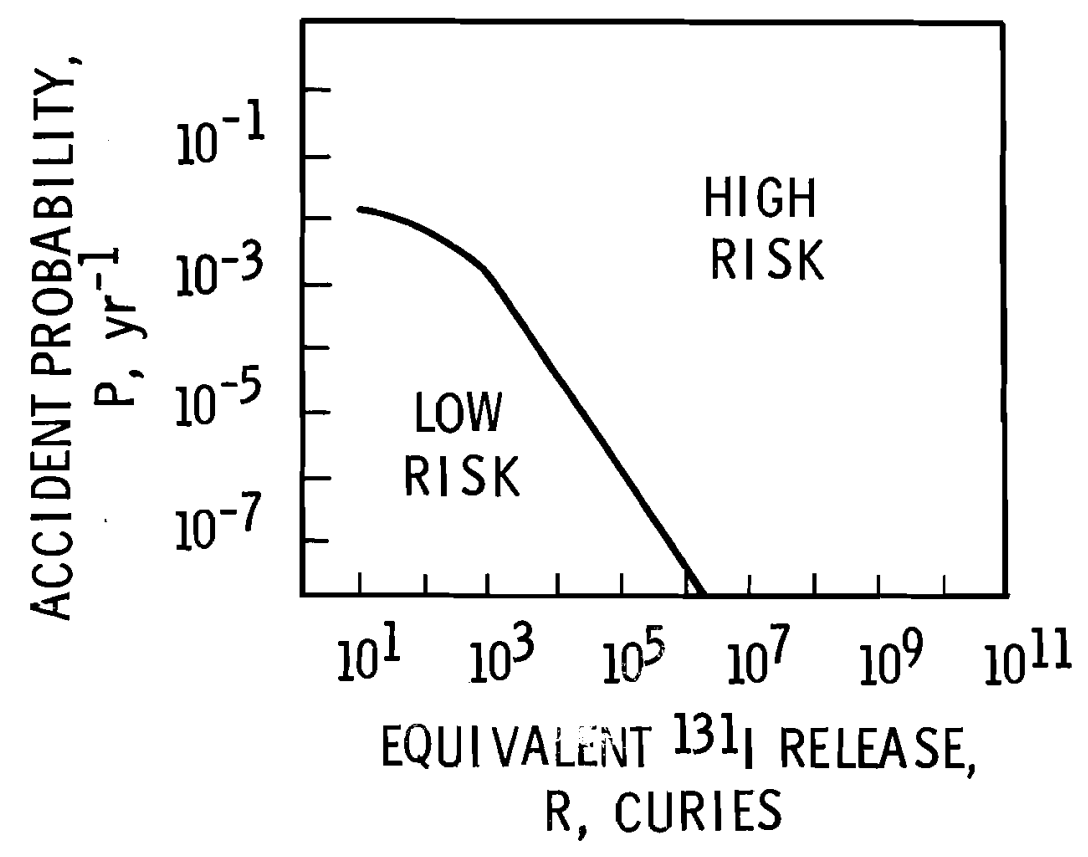

FIGURE 2. Release Criterion (Proposed by Farmer)

a. More recently, Farmer and coworkers have returned to use of a slope of -1 , giving lines of equal risk. 
Farmer concluded: (1) There is no need to obtain greater precision in estimation of release quantities than in that of release probabilities; (2) if a single safety feature reduces a potential release quantity by $n$ orders of magnitude, then the reliability of this feature should be established to at least a corresponding accuracy, i.e., a failure rate of 1 in $10^{\mathrm{n}+1}$ occurrences.

B. Meleis and Erdmann (2) compared risks associated with Farmer's proposed limit line with other recorded risks. Using age-weighted populations and dose-to-death conversion factors for thyroid cancer and leukemia, a relationship was derived between release quantity $R$ (curies) and yearly individual mortality risks $M$ in the form $M=K R$, where $K$ includes conversion factors and meteorological considerations. An individual situated downwind at the exclusion fence was assumed. The yearly individual mortality risk $\overline{I M R}$ from the total spectrum of accidents represented by the Farmer limit line is

$$
\overline{I M R}=\int M(P) d P=\int_{P=10^{-9}}^{P=3 \times 10^{-2}} K R(P) d P .
$$

It was claimed that extending $P$ to zero does not materially change the result. The calculated individual risk was considerably higher than that from natural events such as lightning $\left(10^{-7}\right.$ to $\left.10^{-6} / \mathrm{yr}\right)$. It was recommended that the limit line be shifted toward lower risks to bring the integrated risk into agreement with those from unavoidable natural events generally accepted as a fact of life.

C. otway et al $^{(3)}$ extended and applied the Farmer approach. The value of $10^{-7} /$ year was selected for the acceptable individual mortality risk at a plant boundary. Dose-to-death conversions included nonzero 
threshold values. Risk was taken to be death from all conceivable accidents, weighted by the respective accident probabilities. Since identification of all accident combinations is impossible, the release spectrum was assumed a continuous function of accident probability. This assumption is expected to place a conservative upper limit on the risk.

A11 releases were assumed to occur with the wind constantly blowing to the most densely populated sector.

The derivation of risk is given:

$$
P \stackrel{\sim}{=} P_{P} \prod_{i} P_{i}
$$

where

$P=$ Probability of a postulated accident per year,

$P_{P}=$ probability of a primary system failure per year, and

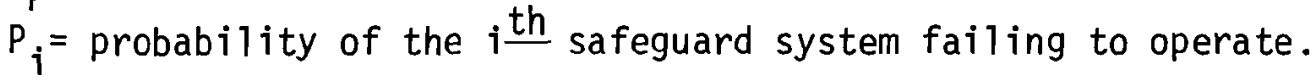

$$
D(P, s)=R(P) \phi(s)
$$

where

$$
D(P, S)=\text { dose in rem, a function of accident probability }
$$

$(P)$ and distance (s) from the source,

$R(P)=$ release in curies ${ }^{131} I$ equivalent, and

$\phi(s)=$ dose in rems per curie ${ }^{131}$ I equivalent released.

$$
M(P, s)=D(P, s) m
$$

where

$$
\begin{aligned}
& M(P, S)=\text { mortality probability, a function of accident probability } \\
& (P) \text { and distance }(s) \text {, and } \\
& m=\text { mortality probability per rem of radiation. }
\end{aligned}
$$

$$
\overline{\operatorname{IMR}}(s)=\int_{P_{1}}^{P_{2}} M(P, s) d P
$$


where

$\overline{\operatorname{IMR}}(s)$ = individual mortality risk per year.

$\overline{\operatorname{IMR}}(\mathrm{s})$ can be used to determine the exclusion distance, $s_{1}$, by selecting a maximum allowable value of $\overline{I M R}$, such as $10^{-7}$ /year.

$$
\overline{T M R}=\int_{s_{1}}^{s_{2}} \frac{2}{\operatorname{IMR}}(s) H(s) d s
$$

where

$\overline{\mathrm{TMR}}=$ total mortality risk to the population, deaths per year, and $H(s)=$ population density as a function of distance, $s$, from the source. No evacuation of the population was considered.

The method was applied in the analys is of PWR fission product release in terms of ${ }^{131}$ I equivalents, with the usual Farmer curve of release vs. probability resulting. Manipulation of the curve by means of Equation (4) resulted in a plot of $\overline{I M R}$ versus $\mathrm{s}$. With an assumed risk limit, the recommended exclusion radius, $s_{1}$, was derived.

The subject of accident chains resulting from earthquakes and other site-induced events was investigated. The importance of such events lies in the possible simultaneous failure of several safety containment systems. It was stated that the risk from earthquakes may be greater than other plant risks. Thus, with present design practice, earthquake risk may be the controlling risk.

D. Otway et al ${ }^{(4)}$ refined the earlier approach. ${ }^{(3)}$ Calculation of the probability density function of fission product release for a sample of the complete accident population was discussed. The sample, limited by human imagination, is not completely random. However, the sample is not intentionally biased if common mode failures are included.

Risk estimates were given for a Los Alamos reactor, again with a typical Farmer curve resulting. The effects of radiation considered 
included acute and late somatic, nonspecific life shortening, and genetic. No dose-effect threshold value was used. Confidence levels and common mode failures were discussed.

The probability treatment was somewhat different from that in Equations (2) through (5). An attempt is made here to summarize pertinent portions of the derivation. From the probability vs. release curve the probability density function $P(R)$ was obtained, where $R$ is the quantity released. Similarly to Equation (2), the downwind dose $D$ from a release is

$$
D(s)=\phi_{i}(s) R
$$

where

$s$ again is distance from release point, $i$ represents the $i$ th Pasquill weather condition, and the release-to-dose conversion $\phi$ is now a function of the Pasquill weather condition $i$ as well as of distance $s$.

Similarly to Equation (3),

$$
M=(D-\alpha) m
$$

where

$\alpha=$ the dose-effect threshold, taken to be zero.

The individual risk as a function of weather and distance appears to be, as in Equation (4),

$$
\overline{\operatorname{IMR}}_{i}(s)=\int_{0}^{\infty} M(D) P(D \mid s, i) d D
$$

For a given direction $\theta$ the individual risk can be summed over weighted weather conditions as

$$
\overline{\operatorname{IMR}}(\theta, s)=\sum_{i=1}^{N} \overline{\operatorname{IMR}}_{i}(s) h_{j}(\theta) g_{j}
$$


where

$h_{i}(\theta)$ is the conditional probability density function of wind direction $\theta$ for the $i^{\text {th }}$ Pasquill weather condition, $g_{i}$ is the probability of the $i^{\text {th }}$ Pasquill condition occurring, and $N$ is the total number of Pasquil1 conditions used.

The total population risk in deaths per year is

$$
\overline{\mathrm{TMR}}=\sum_{\mathrm{s}=\mathrm{s}_{1}}^{\infty} \sum_{\theta=0^{\circ}}^{360^{\circ}} \overline{\operatorname{IMR}}(\theta, \mathrm{s}) H(\theta, \mathrm{s})
$$

where

$$
\begin{aligned}
H(\theta, s)= & \text { the number of people in direction } \theta \text { and at distance } s, \\
& \text { and } s_{1} \text { again is the exclusion distance. }
\end{aligned}
$$

With the exception of the introduction of angular dependence (of wind equations and population) and of Pasquil1 weather variations, this derivation is nearly the same as its predecessor in Equations (1) through (5). The main difference is the use of dose rather than release probability as the independent variable.

E. Otway et al ${ }^{(5)}$ made the derivation of Equation (9) more lucid in a later paper concerned with risks of a Plowshare detonation.

There the result was

$$
\overline{\operatorname{IMR}}(\theta, s)=\left[\sum_{i=1}^{N} m D_{i}^{\prime}(s) g_{i} h_{j}(\theta)\right] \quad \int R P(R) d R
$$

where

$P$ is again the probability density function of the release quantity $R$ and $D_{j}^{\prime}(s)$ is now the dose, at a distance $s$ and for the $i^{\text {th }}$ Pasquill condition, arising from a unit release.

The expression for $\overline{T M R}$ is unchanged.

F. Appendix $V$ of the Starr/UCLA risk analysis ${ }^{(6)}$ discussed transportation of nuclear materials. The probability density function of release 
quantity was considered. Transportation accidents were divided into six classes, based on the release into a watercourse. From past records a relative frequency was attached to each class.

Next it was stated that

The degree of contamination will depend on the quantity of radioactive material involved, the fraction released from the package, and the local meteorological and hydrological conditions. To determine the probability of an accidental release of a given amount of radioactivity, it is necessary to estimate the statistical distribution of the fractional radioactivity releases from the container. Obviously, there will be an upper limit on the amount of radioactivity released...

Only class 5 and 6 accidents involve dispersal of radioactive material beyond the vehicle and roadway. For each of these classes, a "small group" simplified model of amount released versus relative probability was postulated as shown below:

\begin{tabular}{|c|c|}
\hline $\begin{array}{c}\text { Amount } \\
\text { Released } \\
\text { (curies) }\end{array}$ & $\begin{array}{c}\text { Relative } \\
\text { Probability }\end{array}$ \\
\hline $0-1000$ & 0.5 \\
\hline $1000-2000$ & 0.0555 \\
\hline $2000-3000$ & 0.0555 \\
\hline • & • \\
\hline$\cdot$ & . \\
\hline - & . \\
\hline $9000-10,000$ & 0.0555 \\
\hline
\end{tabular}

A table of quantity released versus frequency was constructed from the two sets of data previously described plus data for overall accident frequency. Unfortunately, in continuing this analysis to the point of dose calculations, only "maximum credible" releases were evaluated. The calculated average release quantity was two orders of magnitude less than that of the "maximum credible" release. 
G. Appendix III of the same report, ${ }^{(6)}$ regarding a hypothetical 1000 MWe LMFBR, is one of the most thorough probabilistic nuclear safety analyses in print at this time. The Farmer approach described previously was generally followed. Fault tree analysis included upper and lower limit probabilities (without and with safety systems) for six basic accidents arising from many causes.

The author was almost immediately confronted by the spectrum problem:

At this point, an apparent dilemma became evident. For example, there exists a wide spectrum of loss of flow accidents which can all potentially lead to radioactive releases of different severity. However, the loss of flow accident fault tree is a generalized model. Hence, the question arises, what release is it really related to? This problem was resolved by selecting a release for each general type of accident which might be characterized as the "most probable" release but somewhat biased in the conservative (high) direction. It must be noted, that these "most probable" releases assume that all engineered safety features are in the failed state at the time of the accident.

Tornadoes more severe than the design basis tornado were considered. This is the first example, discovered in the present survey, of consideration of an event severity spectrum. Earthquakes were treated in an analogous manner:

Since our fault trees are treated probabilistically and, a1so, since they do include earthquake events, it became imperative for us to correlate earthquake magnitude with probability of occurrence. Fortunately, the task turned out to be not too difficult. With the use of curves similar to Figures 2 [earthquake frequency versus magnitude] and 3 [affected area versus magnitude] one can, with some mathematical manipulations, get the necessary answers.

Equations (3) through (5) were applied in the study. No weighting of meteorological conditions was included. As in most risk studies, population density was taken to be constant. The variation of dose with angle from the downwind direction was accounted for by an integration over al1 angles within an assumed sector width. Most other analyses have considered only the effects directly downwind. The risk calculated by means of Equation (5) was similar to that calculated for a 1000 MWe PWR by 0tway. 
H. The summary volume of the Starr/UCLA report ${ }^{(6)}$ reiterates the inadequacy of the "maximum credible" concept for effective public communication of risks:

The public is confused and misled when leaders and experts make statements with qualitative comparisons such as "safe" versus "unsafe," "credible" versus "incredible," "cautious" versus "incautious," "reasonable" versus "unreasonable" - in reference to the risk of injury to the individual. These terms imply absolute boundaries of risk which do not really exist. Furthermore, there is danger in such qualitative comparisons undermining public confidence particularly when one "expert" will decry as intolerable what another feels is an adequate level of safety. ...we must ask the question "how safe is safe enough?" and provide quantitative guidelines which will make possible a rational approach towards defining acceptable levels of public risk.

Data were presented showing routine public acceptance of mortality risks arising from involuntary exposure to socio-technical systems as a function of benefits attributed to the systems. This is one example of an answer to the question "how safe is safe enough?"

I. The Rasmussen/MIT study ${ }^{(9)}$ currently underway $(a)$ is apparently following the basic concepts outlined previously:

The methodology being employed will predict the most probable consequences of a given accident as well as the probability that smaller or larger consequences may result. This will provide a much better understanding of the spectrum of possible consequences. I believe that the understanding most people have of serious nuclear accidents has been greatly distorted by the "worst case" analysis used in previous studies.

Identification of accident sequences and assignment of probabilities are performed by means of fault trees and event (decision) trees. Combinations of an initiating event and the response of the various engineered safety features are modeled on decision trees. The probabilities of key events in the decision trees are evaluated by means of fault trees. Each key event is defined as the top, undesired event of a fault tree.

One study task is devoted to analysis of the "dispersed source," i.e., release fraction and characteristics. Another task includes estimates of health effects (deaths and latent cancers, not merely dose)

a. The draft report of the Rasmussen reactor safety study (the most extensive investigation to date) was released shortly after the final writing of this PNL study. 
resulting from release. "After a complete analysis of the event tree, it is possible to generate a histogram..... This curve which presents accident frequency vs. consequences demonstrates the overall risks to the public and allows computation of expected, or probability-weighted, consequences."

J. The AEC transportation study WASH-1238 $(10)$ includes an accident probabilities analysis (Appendix A) which is mathematically similar to that of Reference 6 , Appendix $V$. Accidents were divided into five severity categories on the basis of various combinations of four impact speed categories and four fire categories. Appendix B derives the probability of $\mathrm{N}$ or more persons receiving a dose of $D$ or more mrem per year, given population densities and the probabilities associated with the Pasquill weather types.

K. A Battelle, Pacific Northwest Laboratories (PNL), transportation safety study (7) for the AEC is developing methodology to assess the risk of radioactive material transport. Summarized and paraphrased here is the discussion on the governing equations:

For an event chain initiated by a vehicle accident, the probability of release of a certain kind and amount of material, P, may be written

$$
P=\sum_{a T 1} A, S, F \quad P_{A} P_{S} P_{F} P_{R}
$$

where $P_{A}$ is the probability of a vehicle accident of a certain type and intensity, a function of such variables as distance travelled, type of vehicle, and traffic conditions. $P_{S}$ is the conditional probability, given that a vehicle accident of a certain type and intensity has occurred, that the package will be subjected to a certain type and level of generalized stress, such as impact energy, deceleration force, or heating by fire; it is a function of the type of vehicle, the type and intensity of the accident, and the type and level of package stress. $P_{F}$ is the conditional probability, given that the package has been subjected to a certain type and level of stress, that the package will experience a failure of a certain type and magnitude; it is a function of the type and level of stress, 
the package design, and the type and magnitude of failure. $P_{R}$ is the conditional probability, given that the package has experienced a failure of a certain type and magnitude in response to a certain type and level of stress, that a certain type and amount of radioactive material will be released; it is a function of the package failure, the package stress (particularly, whether or not a fire is present) the package design, and the content release.

For an accident chain initiated by package failure during normal transportation conditions, the overall probability of a certain kind and quantity of release for a given shipment is:

$$
P^{\prime}=\sum_{a 11 F} P_{F}^{\prime} P^{\prime}{ }_{R} \text {. }
$$

$P^{\prime}{ }_{F}$ is the probability of a certain type and magnitude of package failure; it is a function of the package failure, the design, quality control, and maintenance of the packaging, and the package environment. $P_{R}{ }_{R}$ is the conditional probability, given that a certain package failure has occurred, that a certain release will occur.

The risk associated with a system is the expected (or average) loss experienced by the system. Thus the risk associated with a certain type of undesired event (characterized by the subscript $i$ ) may be written:

$$
R_{i}=P_{i} C_{i}, \quad i=1,--, m
$$

where $P_{i}$ is the probability of that type of event and $C_{i}$ is the expected consequence of that type of event. Radiological risk may be expressed as the annual dose in man-rem. $P_{i}$ would then be the annual frequency (events/ year) and $C_{i}$ the radiological consequence (man-rem/event). Provided that the types of undesired events are mutually exclusive, the total risk of the system is then

$$
R=\sum_{i=1}^{m} R_{i} .
$$


The authors recommended that calculation of the consequence factors $c_{j}$ be done by means of techniques involving deterministic rather than probabilistic elements. Subsequent discussion with one of the authors indicates that this decision may be reversed.

Population modeling was included. The U.S. was divided into four zones, a representative state being chosen for each zone. Three population densities--characteristic of cities, suburban, and rural--were included for each zone.

L. Smith and Greenborg ${ }^{(8)}$ estimated incremental benefits and risks associated with use of cardiac pacemakers powered by Betace ${ }^{\circledR}$ nuclear batteries. The work was in response to a request of AEC Regulatory, Product Standards Branch, for completion of a preliminary risk/benefit estimate by developing the methodology and making reasonable simplifying assumptions.

The probabilistic treatment of accidental release involved spectra of events related to the release process. Nine types of accidents or initiating events involving implanted pacemakers were considered. Examples are cremation, firearms incidents, and impact.

For each accident type, a "spectrum" of event frequency versus severity level (e.g., ${ }^{\circ} \mathrm{F}$ for fire, ft-lb muzzle energy for firearms) was derived from accident statistics, engineering analysis, and, where necessary, engineering judgment. Rather than a continuous spectrum of severity level, a histogramtype presentation was used. (a) The severity spectrum was divided into 5 to 15 bands (not necessarily of equal width), depending on the data available and the degree of resolution required. (Essential to this approach is removal of upper "maximum credible" limits on the severity level. The maximum severity level is generally taken to be essentially infinite. This is similar to the technique developed independently by Godbout. ${ }^{(6)}$ Thereby all "what if. . .?" questions regarding extreme severity levels are automatically answered. Whether the particular severity level is "credible" to a given nuclear safety engineer is irrelevant. The frequency of occurrence of extreme severity levels was found to be so low that the overall release

a. The diagrams were not "proper" histograms because the scales were openended and were unequally divided. More correct designations are frequency distribution (Figures 3 and 6 ) and probability distribution (Figure 4). 
probability was generally unchanged, as shown later.) Figure 3 shows spectra representative of the two types found in the Betace ${ }^{\circledR}$ studies. The process discussed in this paragraph is essentially that represented by the product $P_{A} P_{S}$ in Equation (12) from McSweeney et a1. (7) For nontransportation environments the $P_{A}$ and $P_{S}$ terms often degenerate to a single term.

For each accident type a second spectrum, divided into the same severity levels as before, was derived for the conditional probability of containment breach as a function of severity level. This is a representation of the $P_{F}$ term of Equation (12) and was based on test data, engineering analysis, and, where necessary, engineering judgment. Only one basic shape of this diagram, shown in Figure 4, was found for the Betace ${ }^{\circledR}$ accident types.

The nonzero conditional breach probability at low generalized stress levels represents the random flaws caused by defects in materials and manufacturing. The 0.5 value of conditional probability of breach is close to the calculated failure level, if the structural or thermal analys is has been done accurately. The spectrum shape in Figure 4 is essentially the integral of a curve such as that of Figure 5 , showing a characteristic frequency distribution of material strengths. (12) Care must be exercised, however, in treating severity bands of unequal width.

The two spectra for each type of accident were then multiplied together (events/year $\times$ breach/event = breach/year, all as functions of severity leve1). All accident types examined gave the basic shape in Figure 6. In terms of breaches/year, accidents of low severity are of lesser concern because the conditional probability of containment breach (Figure 4) is so low. Accidents of extreme severity are of lesser concern, in terms of breaches/year, because these levels occur so infrequently (Figure 3 ). The central bulge in the region of moderately severe events is of greatest interest in reducing the number of breaches. 
A. Firearms Incidents

\begin{tabular}{|c|c|c|}
\hline Muzzle E & Energy $(f t-1 b)$ & $\begin{array}{c}\text { Pacemaker } \\
\text { Hits/yr-20,0 } \\
\text { Patients } \\
\end{array}$ \\
\hline $\begin{array}{r}0 \\
120 \\
200 \\
300 \\
400 \\
500 \\
750 \\
1000 \\
1500 \\
2000 \\
3000 \\
4000 \\
500\end{array}$ & $\begin{array}{l}-\quad 120 \\
-\quad 200 \\
-\quad 300 \\
-\quad 400 \\
-\quad 500 \\
-\quad 750 \\
-\quad 1000 \\
-\quad 1500 \\
-\quad 2000 \\
-\quad 3000 \\
-\quad 4000 \\
-5000\end{array}$ & $\begin{array}{l}0.008237 \\
0.000596 \\
0.000290 \\
0.000290 \\
0.000290 \\
0.000100 \\
0.000302 \\
0.000133 \\
0.000073 \\
0.000087 \\
0.000002 \\
\approx 0.0 \\
\approx 0.0\end{array}$ \\
\hline 5000 & & 0.0104 \\
\hline
\end{tabular}

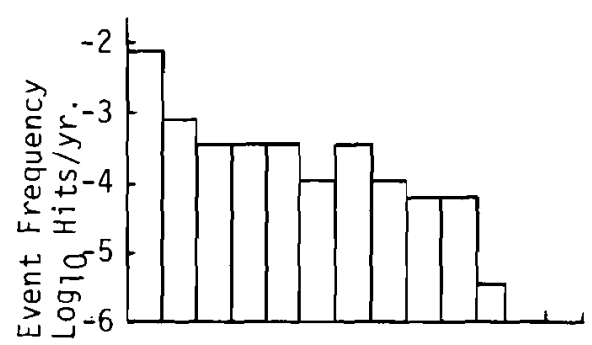

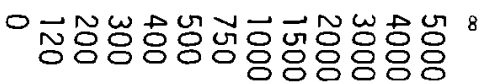

Muzzle Energy (ft-lb)

B. Accidental Cremation

\begin{tabular}{ll} 
Peak Temperature $\left({ }^{\circ} \mathrm{F}\right)$ & $\begin{array}{l}\text { Betacels } \\
\text { yr-20,000 }\end{array}$ \\
\hline$<1400 \mathrm{max}$. & 0.01 \\
$1400-1600$ & 0.05 \\
$1600-1800$ & 0.13 \\
$1800-2000$ & 0.25 \\
$2000-2200$ & 0.54 \\
$2200-2300$ & 0.07 \\
$2300-2400$ & 0.02 \\
$2400-2500$ & 0.005 \\
$2500-2600$ & 0.0005 \\
$>2600$ & $\underline{0.00005}$ \\
& 1.08
\end{tabular}

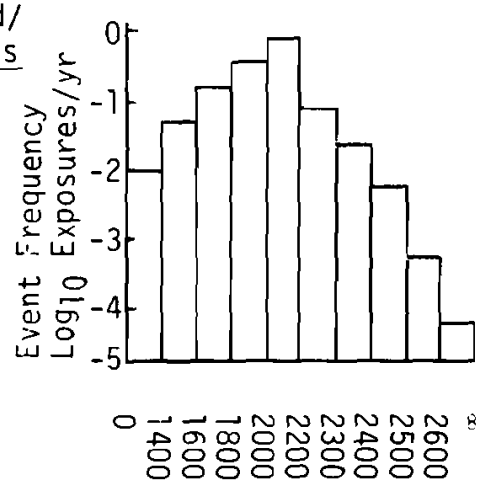

Temperature $\left({ }^{\circ} \mathrm{F}\right)$

FIGURE 3. Examples of Event Frequency Distribution for Betacel ${ }^{\circledR}$ Nuclear Battery. (8) Note that horizontal axes are not linear scales, so caution must be exercised in the manipulation of data presented in this manner. 
A. Firearms Incidents

\begin{tabular}{ccc}
$\begin{array}{ccc}\text { Muzzle } \\
\text { Energy } \\
\text { (ft-1b) }\end{array}$ & $\quad \begin{array}{l}\text { Estimated } \\
\text { Conditional } \\
\text { Probability } \\
\text { of Breach }\end{array}$ \\
\hline- & & $10^{-4}$ \\
120 & & $10^{-2}$ \\
200 & & $3 \times 10^{-2}$ \\
300 & & $10^{-1}$ \\
400 & & $5 \times 10^{-1}$ \\
500 & & $\sim 1$ \\
750 & & $\sim 1$ \\
100 & & $\sim 1$ \\
1500 & $\sim 1$ \\
2000 & $\sim 1$ \\
3000 & $\sim 1$ \\
4000 & $\sim 1$
\end{tabular}

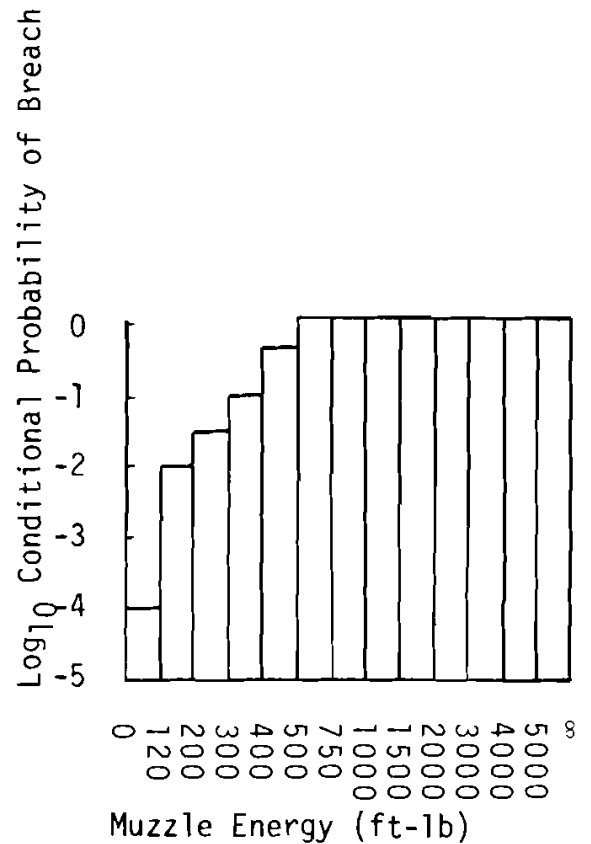

B. Accidental Cremation

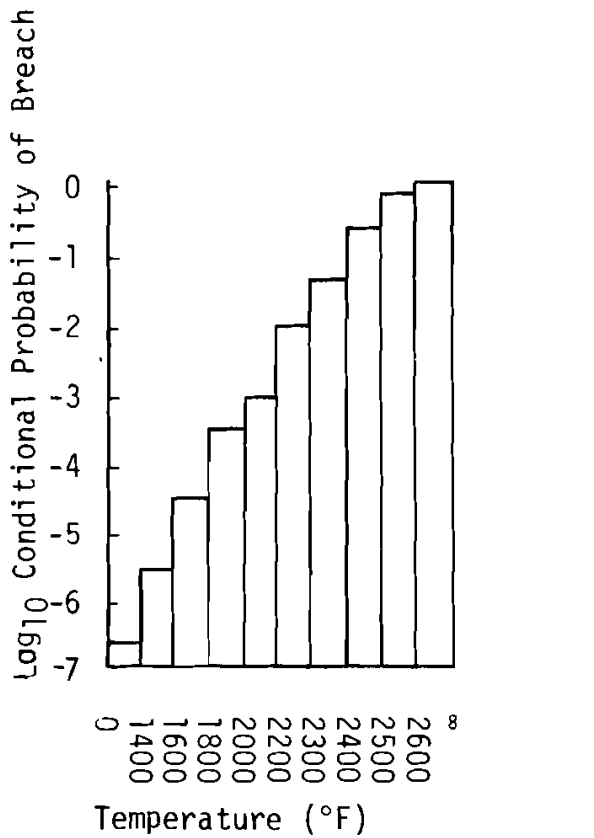

\section{FIGURE 4. Examples of Estimated Distribution of Condjtional Probability} of Breach for Betacel ${ }^{\circledR}$ Nuclear Battery. (8) Note that horizontal axes are not linear scales. 
BNWL -1848

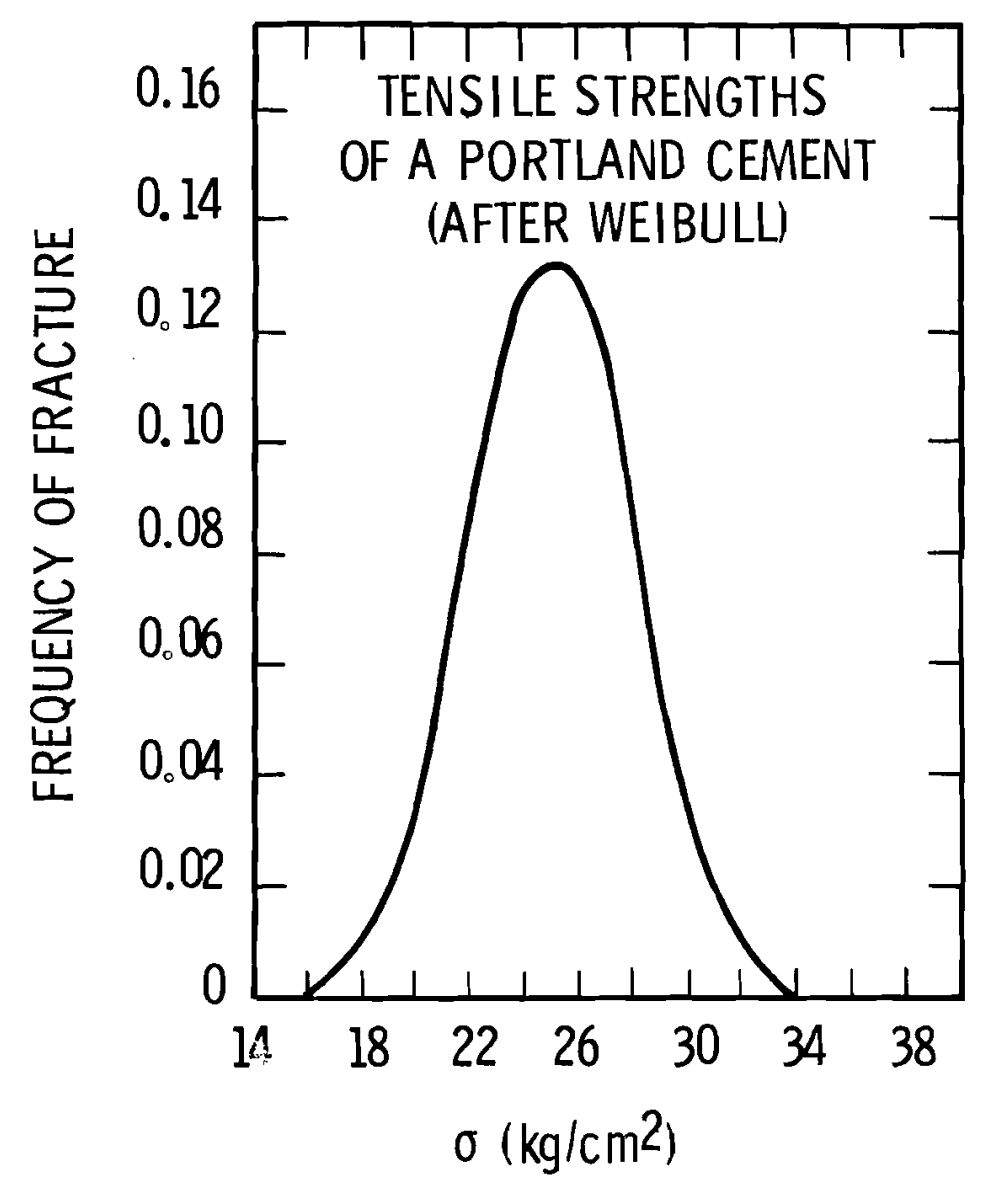

FIGURE 5. Frequency Distribution of Observed Strengths $(12)$

The spectrum of releases, corresponding to $P_{R}$ in Equation (12), was examined very briefly. Not all breaches lead to the same quantity of transportable radioactive material. Releases without a thermal driving force were assumed to occur instantaneously and were classified by the fraction of inventory released and the instantaneous release radius. This double classification resulted in two numbers being assigned to the breach possibility for each of the 5 to 15 severity levels in each of the nine accident types. Only three values each of inventory release fraction and instantaneous release radii were treated, i.e., a nine-group model. More precise analysis requires a much finer breakdown. The entire quantity of radioisotope released was assumed to exist in a very fine powder, completely respirable. Thermally driven releases were handled in a similarly simple manner. 
A. Firearms Incidents

\begin{tabular}{|c|c|}
\hline $\begin{array}{l}\text { Muzzle } \\
\text { Energy } \\
(f t-1 b)\end{array}$ & Breaches/year \\
\hline $0-120$ & $8.2 \times 10^{-7}$ \\
\hline $120-200$ & $6.0 \times 10^{-6}$ \\
\hline $200-300$ & $8.7 \times 10^{-6}$ \\
\hline $300-400$ & $2.9 \times 10^{-4}$ \\
\hline $400-500$ & $1.4 \times 10^{-4}$ \\
\hline $500-750$ & $1 \times 10^{-4}$ \\
\hline $750-1000$ & $3 \times 10^{-4}$ \\
\hline $1000-1500$ & $1.3 \times 10^{-4}$ \\
\hline $1500-2000$ & $7.3 \times 10^{-5}$ \\
\hline $2000-3000$ & $8.7 \times 10^{-5}$ \\
\hline $3000-4000$ & $2 \times 10^{-6}$ \\
\hline $4000-5000$ & $<10-7$ \\
\hline \multirow[t]{2}{*}{$>5000$} & $<10^{-7}$ \\
\hline & $1.14 \times 10^{-3}$ \\
\hline
\end{tabular}

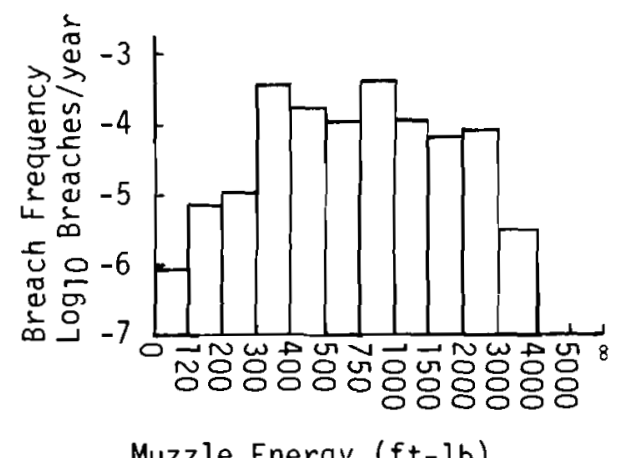

B. Accidental cremation

\begin{tabular}{|c|c|}
\hline $\begin{array}{l}\text { Peak } \\
\text { Tempera- } \\
\text { ture } \\
\left(^{\circ} \mathrm{F}\right)\end{array}$ & $\begin{array}{l}\text { Breaches/ } \\
\text { year }\end{array}$ \\
\hline$<1400$ & $3 \times 10^{-9}$ \\
\hline $1400-1600$ & $1.5 \times 10^{-7}$ \\
\hline $1600-1800$ & $3.9 \times 10^{-6}$ \\
\hline $1800-2000$ & $7.5 \times 10^{-5}$ \\
\hline $2000-2200$ & $5.4 \times 10^{-4}$ \\
\hline $2200-2300$ & $7 \times 10^{-4}$ \\
\hline $2300-2400$ & $10-3$ \\
\hline $2400-2500$ & $10^{-3}$ \\
\hline $2500-2600$ & $3.5 \times 10^{-4}$ \\
\hline$>2600$ & $<5 \times 10^{-5}$ \\
\hline & $3.7 \times 10$ \\
\hline
\end{tabular}

Muzzle Energy (ft-lb)

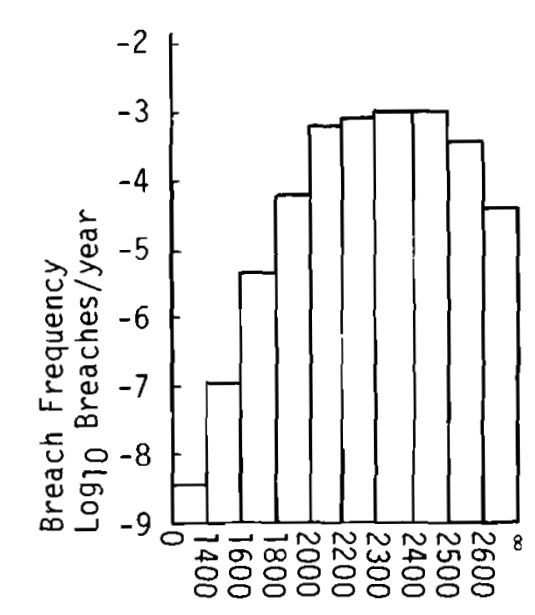

Temperature $\left({ }^{\circ} \mathrm{F}\right)$

FIGURE 6. Predicted Frequency Distribution of Containment Breaches for 20,000 Patients With Betace1@ Nuclear Batteries. (8) Note that horizontal axes are not linear scales. 
BNWL-1848

A simplified U.S. population model was developed. People were assumed to be located in only four types of "towns," each type having a different inner city/suburb population ratio and different population densities for inner city and suburbs. Each "town" type was variable in total population so as to accommodate all cities within a given range of total population. Each type was weighted, based on U.S. statistics.

The release spectra were combined with the population model and P.squill-type dispersion analysis, integrating over all angles from the dounwind direction. A few representative cases were carried through the cnalysis. A weighting factor was applied to the remaining cases so that each release was weighted by its relative probability and the probabilities of population densities.

M. The AEC reactor safety study WASH-1250 ${ }^{(13)}$ reviews in Chapter 6 many of the concepts presented in the publications discussed herein. Farmer-type curves are included.

\section{A PROBABILISTIC APPROACH TO RISK ANIALYSIS}

"We must avoid the trap of applying elaborate mathematics to a poor mode1. It is better to apply simple mathematics to a better model." (14)

This section derives a mathematical framework for probabilistic nuclear risk evaluation, integrated where possible with fault tree methodology. Recause the resulting expressions are complex, the subject of evaluation is also discussed.

A. Web of Events. A schematic diagram of transportation accident events (7) (Figure 7) provides illustrative background for the approach developed herein. To summarize and paraphrase:

The points (in Figure 7) represent types of events, some of which are linked by lines indicating a nonzero probability of occurring in the same accident chain. Time increases along the horizontal coordinate. The vertical coordinate merely provides a way of plotting distinct types of events. At the top is a list of six general classifications of events, as they occur in an accident chain. Initiating events primarily involve the 
BNWL- 1848

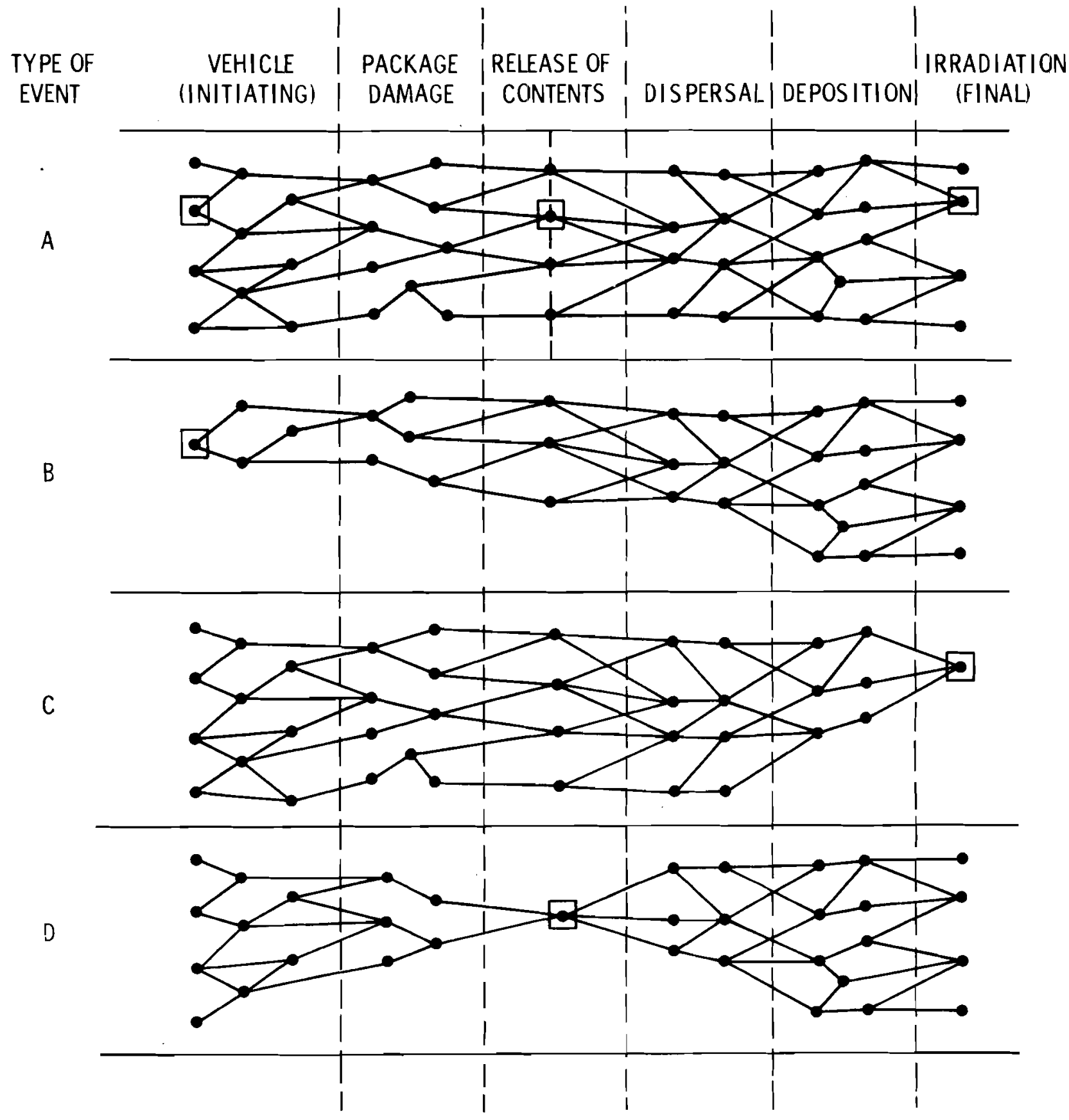

FIGURE 7. Generalized Web of Events in Vehicle Accidents (7) 
vehicle, such as collision or derailment. Next are events, such as secondary collision, burning and melting, which damage the package. Next are the actual releases of certain types and amounts of radioactive material. Next are events related to the dispersal of contents, governed primarily by the presence of fire and the weather and topography in the immediate vicinity of the accident. Next are events related to the deposition of contents, governed by environmental and land use factors. Finally are events of actual exposure, influenced primarily by population density and radiological factors.

Part $A$ is intended to indicate the total web of possible events. Parts $B, C$ and $D$ indicate three ways of dividing the problem into smaller pieces, to be followed by integrating the web back together so as to obtain the total or correct result. In $B$, one of the mutually exclusive initiating events is followed along widening paths to the final events, as in a decision tree analysis. In $C$, one of the mutually exclusive final events is selected for study, and all paths leading to it are analyzed, as in a fault-tree analysis. In Part D (the approach in Reference 7), one of the mutually exclusive release events is selected for study. All preceding events are handled in the manner of a fault tree analysis, while consequent events are handled in the manner of a decision tree analysis. The problem is neatly divided into two parts, the interface of which is the release of a certain kind and amount of radioactive material. The first part includes mechanical and chemical events falling generally into the domain of engineering. The second part includes environmental and biological events falling into other scientific disciplines.

If a complete set of mutually exclusive events (consisting of the release of certain kinds and types of radioactive materials) is selected and the probability and radiological consequences of each type of release are calculated, then a measure of risk can be obtained.

Analys is of a second class of accidents, initiated by inherent package failures, is identical except that the two categories of vehicle and 
package damage events are replaced by a single category of package failure events. Release events still play the key role of categorizing and interfacing the subsystem analyses.

The approach followed herein is that of Part D, with special attention given to the distribution of release quantities for each type of release. One might imagine that each point for Part $A$ under Release of Contents (Figure 7) is "clipped" or isolated. Events leading up to each point are analyzed. Events proceeding from each point are analyzed. The two parts of the web are then rejoined to give the total flow of events. Caution is required, however, in treating those prerelease events which can alter the postrelease analysis and prevent complete decoupling of the web. Examples are earthquakes, which could alter aquifers in the release area, and tornadoes, which would temporarily alter local meteorology.

B. Events Up Through Release. The transportation accident case is used because it is quite general. Nontransportation accident analys is can generally be treated as a special case of this, as shown below. The present derivation builds upon ideas presented in References 7 and 8 , commencing with Equation (12) herein.

$$
P=\sum_{\text {a11 }} A, S, F P_{A} P_{S} P_{F} P_{R}
$$

where

$P$ is the probability density function for release of a given type and amount of material;

$P_{A}$ is the probability density function for an accident of a given type and intensity;

$\mathrm{P}_{S}$ is the conditional probability density function, given that an accident of a certain type and intensity has occurred, that the package will be subjected to a certain type and level of generalized stress; 
$P_{F}$ is the conditional probability density function, given that the package has been subjected to a certain type and level of generalized stress, that the package will experience a failure of a certain type and magnitude; and

$P_{R}$ is the conditional probability density function, given that the package has experienced a failure of a certain type and magnitude, that a certain type and amount of radioactive material will be released.

The following assumptions are now made:

(1) The probability density function for accident type $i$ and intensity VSL (Vehicle Severity Level) can be expressed for a given type of vehicle over a given route as

$$
P_{A_{i}}=f_{1_{i}}\left(V S L_{i}\right) \text { for every accident type } i
$$

on a per mile, per shipment, per year or other suitable basis. $P_{A_{i}}$ is taken to be independent of the type of radioactive material and of package characteristics. (Note: VSL will be the independent variable for integration over vehicle severity level. The caution regarding proper scaling for integration, stated in connection with Figure 3, applies here also. The subscript $i$ in $V S L_{i}$ refers to that variable as applied to accidents of type $i$, not to severity level i.)

(2) The conditional probability density function relating accident type $i$ and intensity VSL to the type $j$ and intensity PSL (Package Severity Level) of generalized stress experienced by the package can be expressed as

$$
P_{S_{i j}}=f_{2_{i j}}\left(V S L_{i}, P S L_{j}\right) \text { for every } i, j \text { combination }
$$

for a given package type and for the vehicle type given above. The above Note applies to PSL also. $P_{S_{i j}}$ is taken to be independent of the type of radioisotope. The general $i j$ dependence allows "cross-product" situations 
such as a package fire environment stemming from vehicle impact and mechanical stresses (thermal, internal pressure) stemming from a stationary vehicle fire. Many of these cross-products, however, are expected to be of such low probability as to make their inclusion unnecessary.

(3) The conditional probability density function relating package generalized stress of type $j$ and intensity PSL to package failure of type $k$ and magnitude PFM (Package Failure Magnitude) can be expressed

$$
P_{F_{j k}}=f_{3_{j k}}\left(P S L_{j}, P M_{k}\right) \text { for every } j, k \text { combination }
$$

for the given package type. The expression is simplified in that a given package failure mode is assumed to result from a single type of generalized stress rather than from a combination of different types of generalized stress. No direct dependence on accident severity level VSL is included; such dependence is assumed to enter only indirectly, through the package severity level PSL. The absence of dependence on the type of radioactive material is again assumed, and the previous Note applies to PFM also.

(4) The conditional probability density function relating package failure of type $k$ and magnitude PFM and package stress of type $j$ and magnitude PSL all to the release of radioactive material of type $\ell$ in amount $R$ can be expressed

$$
P_{R_{j k \ell}}=f_{4_{j k \ell}}\left(P S L_{j}, P F M_{k}, R_{\ell}\right) \text { for every } j, k \text {, } \ell \text { combination }
$$

for the given package type. The previous Note applies to $R$ also. Again no dependence on VSL is included.

Based on the above assumptions and on the unit travel basis selected, the overall probability density function for release of a quantity $R$ of material of type $\ell$ is 


$$
\begin{aligned}
& P\left(R_{\ell}\right)=\sum_{k} \int_{P F M_{k_{\min }}}^{P F M_{k_{\max }}}\left\{\sum _ { j } \left[\int_{P S L_{j_{\text {min }}}}^{P S L_{j_{\max }}} P_{R_{j k \ell}}\left(P S L_{j}, P F M_{k}, R_{\ell}\right) P_{F_{j k}}\left(P S L_{j}, P F M_{k}\right)\right.\right. \\
& \left.\left.\left\{\sum_{i}\left[\int_{V S L_{i_{\min }}}^{V S L_{i_{\max }}} \mathrm{P}_{\mathrm{A}_{j}}\left(V S L_{i}\right) \mathrm{P}_{S_{i j}}\left(\mathrm{VSL}_{i}, \mathrm{PSL}_{j}\right) \mathrm{dVSL}_{i}\right]\right\} \mathrm{dPSL}_{j}\right]\right\} \underset{\text { for every } \ell}{\mathrm{dPFM}_{k}}
\end{aligned}
$$

The $\ell$ different types of radioactive material could refer to the physical state of the material (gas, liquid, different types of solid) or to the identity of the radioisotope if different release mechanisms are involved for different radioisotopes.

For nontransport accidents the severe environments are generally imposed directly on the package or containment. In this case, the $P_{A_{j}}$ and $P_{S_{i j}}$ terms condense to $P_{S A_{j}}\left(P_{S L_{j}}\right)$, which is the probability density function (not a conditional probability density function) for an accident environment of type $j$ and severity level PSL being imposed on the package on a per-year, per-mission, or other suitable basis. This situation is illustrated in Reference 8 (see Figure 3 herein). The case $j=1$ is firearms incidents and $j=2$ accidental cremation. Rather than PSL $_{j}$ being taken as continuous, it is divided into $10(j=2)$ and $13(j=1)$ discrete domains, with $\mathrm{P}_{\mathrm{SA}_{j}}$ assumed constant within each segment. This greatly simplifies the calculations.

C. Events Following Release to Air. The present derivation builds upon ideas presented for airborne release in References 3 through 5, commencing with Equation (11) herein.

$$
\overline{\operatorname{IMR}}(\theta, s)=\left[\sum_{j=1}^{N} m D_{j}^{\prime}(s) g_{j} h_{j}(\theta)\right] \int R P(R) d R
$$


where

$P(R)$ is the probability density function, on a yearly or other suitable basis, for release of a quantity R;

$D^{\prime}{ }_{j}(s)$ is the dose, at distance $s$ and for the $j^{\text {th }}$ of $N$ Pasquill weather conditions used, arising from a unit release;

$h_{j}(\theta)$ is the conditional probability density function of wind direction $\theta$ for the $j^{\text {th }}$ Pasquill weather condition;

$g_{j}$ is the probability of the $j^{\text {th }}$ Pasquill condition occurring;

$m$ is the mortality probability per rem of radiation, assumed

constant for subacute exposures; and

$\overline{\text { IMR }}$ is the individual mortality risk on a yearly or other suitable basis.

The quantities $R$ and $P(R)$ are the familiar axes of the Farmer-type release spectrum. They also form the interface between the two parts of the analysis, as described in Section III A.

Equation (11) may be refined by considering $n$ distinct domains of wind velocity, $n$ distinct wind directions and $n$ distinct risk types (different organs or causes of death) so that for each material type $\ell$

$\overline{\operatorname{IMR}}_{\ell}^{a i r}(\theta, s)=\left[\sum_{k=1}^{n} \mu_{k}\left(\sum_{j=1}^{N} g_{j}\left\{\sum_{i=1}^{n} \sum_{m=1}^{n} D_{i j k \ell m}(\theta, s) h_{i m \mid j}\right\}\right)\right] R_{\ell} P\left(R_{\ell}\right) d R_{\ell}$.

Here $\overline{\operatorname{IMR}}_{\ell}{ }^{\text {air }}(\theta, s)$ is the yearly individual mortality risk at location $(\theta, s)$ from airborne release of radionuclide $\ell$. The symbol $\mu_{k}$ is the mortality probability for the $k^{\text {th }}$ risk per rem of radiation. Because radiosensitivity of the various parts of the body differs, doses to different organs must not be simply added. (15) $D_{i j k \ell m}(\theta, s)$ is the dose from inhalation, submersion and other modes of exposure, to the $k^{\text {th }}$ organ of a person 
at location $(\theta, 5)$, arising from a unit airborne release of radionuclide $\ell$ with the $j^{\text {th }}$ Pasquill condition and the $i^{\text {th }}$ wind velocity in the $m^{\text {th }}$ wind direction. The dose could reflect body retention, as well as uptake, by integration over the average remaining life of the population. Reference 15 used a value of 50 years for this quantity. Reference 8 derived a value of 45 years. Decay of the radioisotope during transport may be included. The symbol $h_{i m / j}$ is the conditional probability density function for the $i^{\text {th }}$ range of wind velocity in the $\mathrm{m}^{\text {th }}$ wind direction, given the occurrence of the $j^{\text {th }}$ of $N$ Pasquill conditions. $P\left(R_{\ell}\right)$ is obtained from Equation (20).

For the present, airborne release is assumed to occur over a period of time which is short compared with quantities such as radionuclide halflife. This assumption can be relaxed later by affixing an additional subscript to $D$ relating to the class of release rate, then multiplying by the conditional probability of that class of release rate. This procedure is followed in the next section, which involves the analysis of release to groundwater or surface water.

$$
\begin{aligned}
& \text { Similarly to Equation (10), }
\end{aligned}
$$

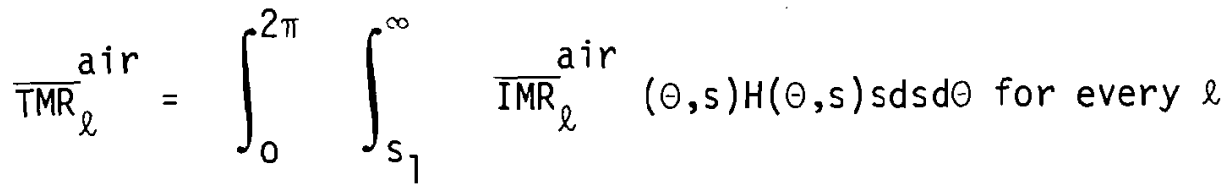

where

$H(\theta, s)$ is the population density function for direction $\theta$ and distance $s$;

$s_{1}$ is the exclusion distance; and

$\frac{\mathrm{a}^{\mathrm{i}}}{\mathrm{TMR}_{\ell}}$ is the yearly population mortality risk from airborne release of material $\ell$.

A more general expression results if the dose-mortality conversion is omitted:

$$
\overline{\mathrm{ID}}_{\mathrm{k} \ell}^{\mathrm{air}}(\theta, s)=\left[\sum_{j=1}^{N} g_{j}\left\{\sum_{i=1 \mathrm{~m}=1}^{n} \sum_{i j k \ell m}^{n}(\theta, s) h_{i m \mid j}\right\}\right] \int R_{\ell} P\left(R_{\ell}\right) d R_{\ell}
$$

for every $k, l$ combination 
where

$\overline{\mathrm{ID}}_{\mathrm{k} \ell}^{\mathrm{air}}(\theta, s)$ is the average or expected yearly individual dose or dose commitment to the $k^{\text {th }}$ organ of a person at location $(\theta, s)$ from material of type $\ell$. The left side of Equation (22) similarly becomes $\overline{T D}_{\mathrm{k} \ell}^{\mathrm{a}}$, the total yearly population dose or dose commitment to the $k^{\text {th }}$ organ from material of type $\ell$.

D. Events Following Release to Groundwater or Surface Water. The derivation of this section covers both release directly to surface water and release to groundwater with retention and fractionation by soil columns of various characteristics and effective lengths. The approach is basically the same as that of the preceding section. The resulting equations provide a means of weighting the various transport and other parameters affecting dose and risk in order to derive the expected or average risk associated with a facility or operation. However, the equations in no way facilitate calculation of dose or risk for a given set of parameter values. Numerous computer codes (see Reference 15 for examples) are in existence for such calculations.

For water-transported radioactive material of type $\ell$, the yearly individual mortality risk for a person located at coordinates $(\Theta, s)$ from the release point is, with $P\left(R_{\ell}\right)$ from Equation (20),

$$
\operatorname{IMR}_{\ell}^{\text {water }}(\theta, s)=\left[\sum_{k=1}^{n} \mu_{k} \sum_{i=1}^{n} w_{i \ell} \sum_{j=1}^{N} a_{i j \ell} D_{i j k \ell}(\theta, s)\right] \int R_{\ell} P\left(R_{\ell}\right) d R_{\ell}
$$

for every $\ell$.

Here $\mu_{k}$ is used as previously, and $w_{i \ell}$ is the conditional probability that the type $\&$ material released occurs within release rate range $i$ among $n$ ranges of conceivable release rate. The symbol $a_{i j \ell}$ is the fraction of the released material (species $\ell$, release rate range $i$ ) which follows path or aquifer $\mathrm{j}$, among the $\mathrm{N}$ such paths considered, to some means of contact with man. Some or all of the $N$ paths may involve soil retention and fractionation; some or all of the $N$ paths may represent release directly to a 
man-used water supply. The objective of this notation is to allow maximum flexibility in the pathways analysis. $D_{i j k \ell}(\theta, s)$ is the dose, to the $k^{\text {th }}$ organ of a person at location $(\theta, s)$, resulting from a unit release of material $\&$ at the $i^{\text {th }}$ release rate passing along path $j$. Each $D_{i j k \ell}$ would also include the dose contributions from any daughters formed during transport. Because of the extremely long transport times often encountered, the dose may represent not only that accumulated over 45 to 50 years following release (the average remaining life of the existing population) but that accumulated to infinite time by all succeeding generations of humans at location $(\theta, s) .(16)$ If all people within a city had identical living habits and obtained food and drink from the same source, $D$ for water transport would be independent of $\theta$ (direction) and $s$ (distance) within the bounds of that city. This assumption provides a possible simplification. water

The $\overline{\mathrm{TMR}}_{\ell}$ expression is identical to Equation (22) except for replacement of $\overline{I M R}_{\ell}^{a i r}$ by $\overline{I M R}_{\ell}$ water . The expected individual dose at location $(\theta, s)$ resulting from events during the year (transport, uptake and exposure may occur over a very long period of time) is

$\overline{\mathrm{ID}}_{k \ell}^{\text {water }}(\theta, s)=\left[\sum_{i=1}^{n} w_{i \ell} \quad \sum_{j=1}^{N} a_{i j \ell} \mathrm{D}_{i j k \ell}(\theta, s)\right] \int \mathrm{R}_{\ell} \mathrm{P}\left(\mathrm{R}_{\ell}\right) \mathrm{dR}_{\ell}$

for every $k$, l combination.

E. Evaluation of the Expressions. Although the expressions derived here are lengthy and rather imposing, the notation actually involves nothing more sophisticated than integrations and summations; thus it is the quantity of calculations involved, not their sophistication, that is 1 imiting. Fortunately, simplifications can be made: (1) Integrals will almost certainly be evaluated by numerical integration methods. The functions to be integrated can be replaced by discontinuous histogram-type functions in the marner shown in Section II $L$. The functions $\theta$ and $s$ can be treated in the usual way population distributions are presented in environmental 
reports. (2) The values of subscripts such as $i, j, k, l, m$ must be limited to smali numbers because even a $3 \times 3 \times 3 \times 3 \times 3$ array involves $243 \mathrm{cal}$ culations. With judgment based on sensitivity considerations one can often avoid mapping the entire array. (3) Before a full-scale statistical study is attempted, a first pass through the expressions, based on most probable or nominal values of all parameters, is recommended. This debugging tool serves as a check on later, more involved calculations. A method of successive approximations is advisable. (4) The uncoupling of prerelease and postrelease events simplifies evaluation of each expression.

Releases of a radionuclide in different forms, such as a range of particle sizes, may occur. This can be handled by a prerelease analysis of the percent of release occurring within each of several size ranges. The postrelease analysis can then be conducted for each size range of interest.

References 17 and 18 provide excellent examples of application of a methodology similar in spirit to that derived here. Probability distributions of both failure magnitudes and meteorological conditions are included. The technique of replacing integrals with several discrete ranges of the variable of interest is clearly demonstrated.

Finally, Farmer's statement regarding the relative unimportance of exact calculations (page 3 ) should be recalled. Since many quantities analyzed are uncertain to a factor of 2 or more, the important ingredient is a logical procedure.

IV. INTEGRATION OF THE APPROACH WITH FAULT TREE METHODOLOGY

\section{A. Background}

Fault tree analysis $(14,19)$ is a formalized deductive process for identifying and estimating probabilities of system failure sequences. The procedure is basically to assume an undesired event and systematically work backwards to identify component faults which could cause or contribute to the event. Explicit terminology and symbolism have been developed for the analysis. 
Figure 7 (the schematic diagram of transportation accident events) reveals two ways in which fault trees could be used in nuclear safety studies: (1) As shown in method D, fault trees could be used to study events up through the release of radioactive material, with release being the undesired event. Thus the fault trees would be used to derive the release term, $\int R P(R) d R$. (2) Human irradiation could be designated as the undesired event. Thus the fault trees would cover all series of events, as in method $C$. This second usage is considerably more complex. Section II I noted still another way of using fault trees, covering events up through failure of a specific piece of equipment but not necessarily including release of radioactive material.

The approach chosen for the probabilistic derivation of risk expressions in Section III $A$ was to divide the web of events at the release events, as in method D. With this approach it is often logical to analyze prerelease events by means of fault trees and postrelease events by means of decision trees. (14) Several analysts have recommended or followed this method in part or in whole. The probabilistic derivation herein for postrelease analysis (e.g., variation in wind velocity and direction) embodies the same mathematical principles as those arising in evaluation of decision trees. The main difference is the difficulty of defining acceptable values for dose or mortality risk. There are no obvious "success paths" nor "failure paths." The postrelease paths differ from one another in degree rather than in kind.

Whatever the manner of applying fault trees to nuclear safety studies, fault tree analysis is limited by the requirement that there be only one output from each logic gate and that it be binary. The technique can be applied best to systems whose components exhibit an absolute behavior of either operating as specified or failing completely. It is especially helpful for analyzing complex systems in which primary failures prevail (those occurring within the envelope of equipment qualification test conditions) and in which faults are of the "on-off" variety. It is more difficult to analyze systems whose components can exhibit varying degrees of 
performance (e.g., hydraulic components such as valves, pumps, nozzles, pipes, and pressurizers, that can exhibit partial failure modes) and can induce different accident sequences, depending on their extent of failure. In addition, when important environmental or operational events can exhibit probability distributions of severity level or when the top release event of a fault tree is called upon to assume varying values, the utility of fault tree analysis is reduced.

Although this limitation of fault tree utility has been recognized by several writers, explicit solutions to the problem are in short supply. This section offers some ideas derived from a continuing effort directed at handling these difficulties. The discussion cannot be all-encompassing because of the vast array of fault descriptions which appear in fault trees.

B. Decision Tree Method

One method for alleviating these restrictions involves a decision tree treatment of the portion of the fault tree located above the event which exhibits degrees of failure. ${ }^{(14)}$ This allows for multiple outcome effects and works well if the fault in question lies at or near the top level of the tree. However, if the fault is located well down into the tree, the task can be formidable.

\section{Cut Set Method}

The method anticipated for the PNL safety study within the Waste Fixation Program $(20)$ is to first obtain all important cut sets of the fault tree. (A cut set is a mathematical expression representing a combination of component failures which must occur in order for system failure to occur.) (19) Then, with treatment of each cut set separately, a conditional probability distribution is obtained for the several possible degrees of failure of the fault in question. For each degree of failure the remaining probabilities within the cut set are calculated. Then the results are weighted by the conditional probabilities of each degree of failure. The method is quite general and can conceivably be applied throughout the tree, but it becomes time-consuming if numerous faults within a cut set exhibit this "matter of degree" behavior. 
BNWL-1848

\section{Spectra Multiplication Method}

A method alluded to by Godbout ${ }^{(6)}$ and used by Smith and Greenborg ${ }^{(8)}$ (Section II $L$ of this report) is useful for treating secondary failures-component failures at severity levels beyond the envelope of qualification testing. The derivation of Equation (20) embodies this method, which is basically a stress-strength type of analysis. The method calls for multiplication of the curve of event frequency versus severity level by the curve of conditional probability of component failure versus severity level, followed by summation over a 11 severity levels. If the stressful e:vironment is applied to an intermediate body, such as a surrounding barrier or package, an additional conditional probability curve or spectrum, such as Equation (17), must be included.

The result of the spectra multiplication and summation is incorporated into the fault tree through the inhibit gate accompanying all secondary failure events. (14) The output of an inhibit gate is $K \cdot P_{i n} \cdot P_{\text {in }}$ is the probability of occurrence of the input fault (tornado, earthquake, etc.). $K$ is the fraction of input faults which result in occurrence of the output fault (failure of the body). $(14,19)$ This expression, $K \cdot P_{i n}$, is equal to the summation, over all severity levels, of the product of the two spectra just described. Figure 8 , a simplified section of a fault tree representing failure of a component, illustrates the process for secondary failures from tornadoes and earthquakes. $P_{E}$, the frequency of component secondary failure from earthquakes, is the sum of the product terms of (1) the spectrum of earthquake frequency versus severity level and (2) the conditional probability spectrum of component failure versus earthquake severity level. $P_{T}$, the frequency of component secondary failure from tornadoes, is handled similarly.

Certain types of primary failures--component failures at environmental severity levels within the envelope of qualification testing--can be treated along with the secondary failures. Examples are failures, due to manufacturing defects, at levels of generalized stress which the component would normally be expected to tolerate. The fact that a component is qualified 


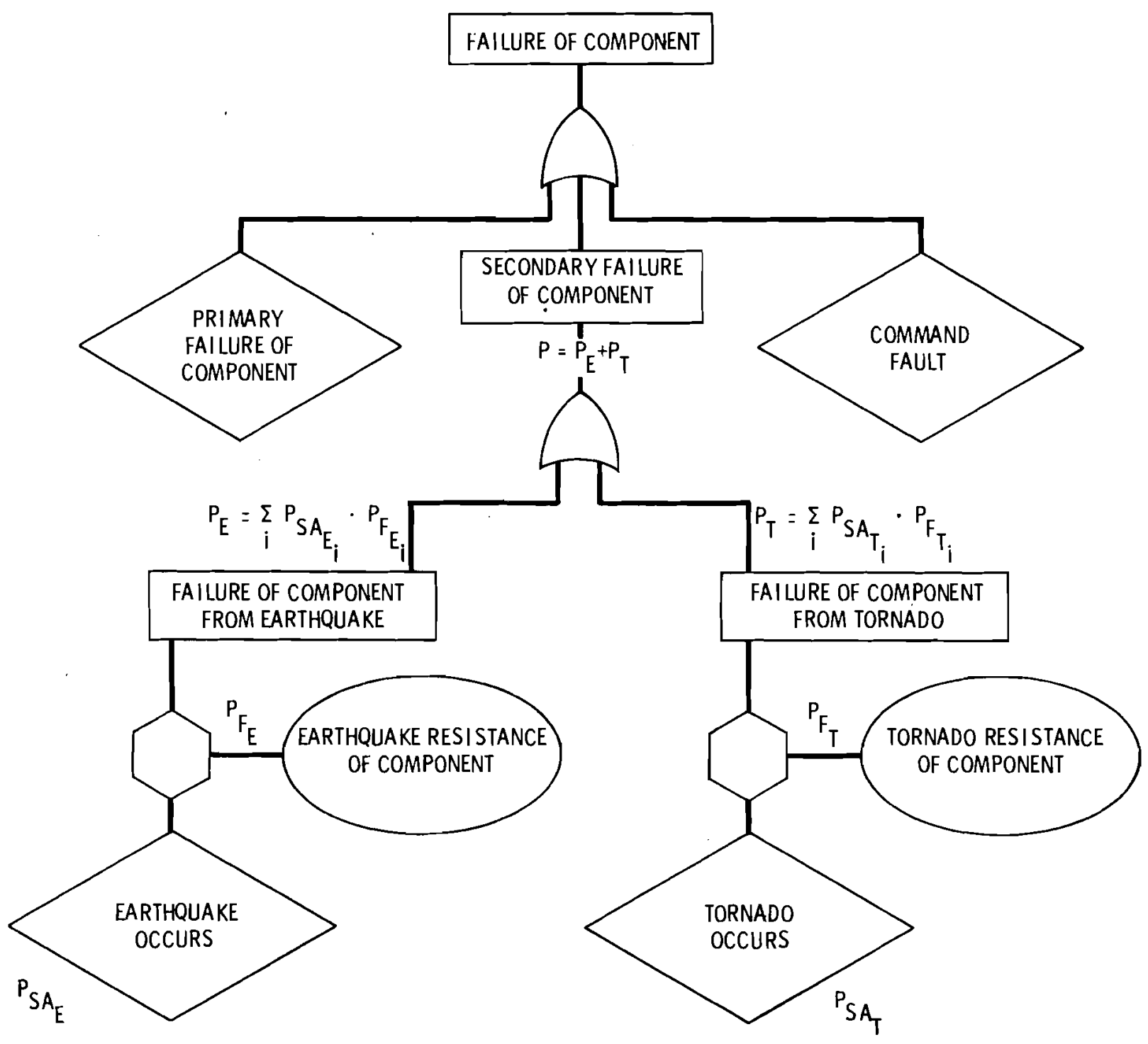

FIGURE 8. Simplified Example Depicting the Use of Fault Trees for Handling Spectra Involved in Secondary Failures. The symbols PSAE, PSAT, $P_{E}$, and $P_{F_{T}}$ are functions of severity level, not single-valued quantities. The subscript $i$ denotes different severity level ranges.

to a given severity level does not guarantee that all units of that design will meet the qualification level nor that the original unit will again satisfy the criterion at a later time. The severity spectrum is extended below the equipment qualification test level to include failures within the qualification envelope, as in Figure 9. Real-life examples are given in Figure 4. 
BNWL-1848

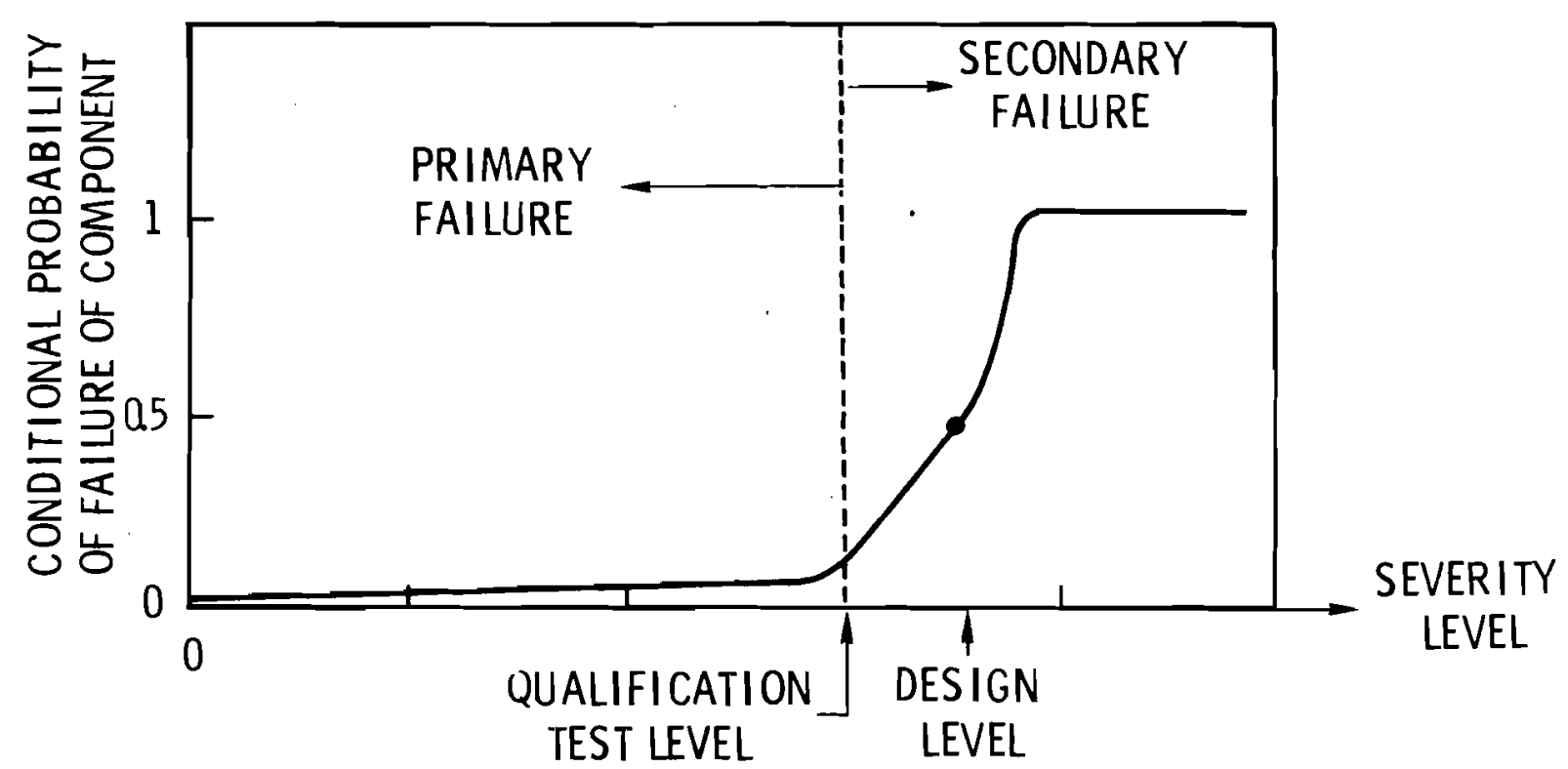

FIGURE 9. Primary and Secondary Failures

Although the frequency of secondary (and some primary) failures can be calculated by spectra multiplication and incorporated into the fault tree, the degree of failure has not been included. How badly did the component fail? How large is the breach in the fuel pin or cask or water basin? Thus the spectrum of failure magnitudes must also be studied, as shown in Equation (18). Incorporating this spectrum and the spectrum of release quantities, as shown in Equation (19), into the fault tree becomes a gargantuan task. While this discussion has not delineated the complete process for incorporating all types of probability spectra into fault trees, the basic concepts for doing so have been described in an effort to point out possible ways to proceed. 
BNWL-1848

\section{REFERENCES}

1. F. R. Farmer, "Reactor Safety and Siting: A Proposed Risk Criterion," Nuclear Safety, vol. 8, pp. 539-548, 1967.

2. M. Meleis and R. C. Erdmann, "The Development of Reactor Siting Criteria Based Upon Risk Probability;" Nuclear Safety, vol. 13, pp. 22-28, 1972.

3. H. J. Otway and R. C. Erdmann, "Reactor Siting and Design from a Risk Standpoint," Nuclear Engineering and Design, vol. 13, pp. 365-376, 1970.

4. H. J. Otway, R. K. Lohrding and M. E. Battat, "A Risk Estimate for an Urban-Sited Reactor," Nuclear Technology, vol. 12, pp. 173-184, 1971.

5. H. J. Otway, R. K.Lohrding and M. E. Battat, "A Method for Estimating the Risk from a Plowshare Detonation," Nuclear Technology, vol. 11, pp. 323-330, 1971 .

6. C. Starr et al., Public Health Risks of Thermal Power Plants, UCLA-ENG-7242, UCLA School of Engineering and Applied Science, 1972.

7. T. I. McSweeney et al., Transportation Safety Studies: The Risk of Plutonium Shipments, BNWL-B-295, Battelle, Pacific Northwest Laboratories, 1973.

8. T. H. Smith and J. Greenborg, Risk-Benefit and Environmental Impact Analys is for Cardiac Pacemakers Powered by Betace18 PM-147 Batteries, DWDL-736-127, Donald W. Douglas Laboratories, June 1973. Summary version presented to American Nuclear Society, November 1973.

9. Atomic Energy Clearing House, vol. 19, no. 40, pp. 46-52, Congressional Information Bureau, October 1, 1973.

10. USAEC Directorate of Regulatory Standards, Environmental Survey of Transportation of Radioactive Materials to and from Nuclear Power Plants, WASH-1238, December 1972. Summary version published in Nuclear Safety, vol. 14, pp. 597-604, November-December 1973.

11. H. S. Denenberg, "Nuclear Energy Is an Insurance Swindle," Prevention, pp. 86-95, January 1974.

12. W. D. Kingery, Introduction to Ceramics, 1960.

13. USAEC, The Safety of Nuclear Power Reactors (Light Water-Cooled) and Related Facilities, WASH-1250, July 1973. 
14. H. E. Lambert, Systems Safety Analysis and Fault Tree Analysis, Lawrence Livermore Laboratory UCID-16238, 1973.

15. D. H. Denham et al., Radiological Evaluations for Advanced Waste Management Systems, BNWL-1764, Battelle, Pacific Northwest Laboratories, Richland, WA, 1973.

16. U.S. Environmental Protection Agency, Environmental Radiation Dose Cormitment: An Application to the Nuclear Power Industry, EPA 520/ 4-73-002, February 1974.

17. I. M. Jacobs, "Assessment of Risk in Reactor Safety," presented to the National Topical Meeting on Water Reactor Safety, Salt Lake City, UT, CONF-730304, March 1973.

18. P. W. Marriott et al., "The Loss-of-Coolant Accident and the Environment - A Probabilistic View," presented to the Winter Annual Meeting of the American Society of Mechanical Engineers, New York, NY, 72-WA/NE-9, November 1972.

19. D. F. Haas1, "Fault Tree Analysis," course notes, Joint Center for Graduate Study, Richland, WA, February 1974.

20. T. H. Smith et al., "A Methodology for Risk Analysis of Nuclear Waste Management Systems," presented to the Annual American Nuclear Society Meeting, Philadelphia, PA, BNWL-SA-4899, June 1974. 
1 AEC Chicago Patent Group

38 Battelle-Northwest

A. A. Churm

230

AEC Technical Information Center

1 Electric Power Research Institute (HQAP) 3412 Hillview Avenue

P.0. Box 10412

Pala Alto, CA 94304

C. Starr

1 Los Alamos Scientific Laboratory (AEC)

P.0. Box 1663

Los Alamos. NM 87544

R. Lohrding

1 Massachusetts Inst. of Technology, (HQAP) Dept. of Nuclear Engineering Cambridge, MA 02139

N. C. Rasmussen
H. C. Burkholder

N. E. Carter

J. P. Corley

D. K. Davis

D. E. Deonigi

J. C. Fox

R. J. Hal1

G. Jansen

J. L. McElroy

T. I. McSweeney

P. J. Pelto

A. M. Platt

K. J. Schneider

T. H. Smith (14)

J. K. Soldat

E. C. Watson

W. K. Weingardner

L. D. Williams

Technical Information (4)

Technical Publications (3)

\section{ONSITE}

1 AEC Richland Operations Office

Research and Development

Programs Division

B. J. Melton

1 Atlantic Richfield Hanford Company

W. J. Van Slyke

1 United Nuclear Industries, Inc.

P. A. Crosetti 